\title{
Self Introduced Rectal Foreign Body in a 16-Year Old Boy: A Case Report and Review of Literature
}

\author{
Volkan Sarper Erikci* \\ Department of Pediatric Surgery, Sağlık Bilimleri University, Tepecik Training Hospital, Izmir, Turkey
}

*Corresponding author: Volkan Sarper Erikci, Department of Pediatric Surgery, Sağlık Bilimleri University, Tepecik Training Hospital, Izmir, Turkey, Tel: +90 542 4372747; E-mail: verikci@yahoo.com

Received: 11 Feb, 2020 | Accepted: 24 Feb, 2020 | Published: 28 Feb, 2020

Citation: Erikci VS (2020) Self Introduced Rectal Foreign Body in a 16-Year Old Boy: A Case Report and Review of Literature. J Surg Open Access 6(4): dx.doi.org/10.16966/2470-0991.209

Copyright: ( 2020 Erikci VS. This is an open-access article distributed under the terms of the Creative Commons Attribution License, which permits unrestricted use, distribution, and reproduction in any medium, provided the original author and source are credited.

\section{Introduction}

Colorectal Foreign Bodies (FB) are not uncommon in the Emergency Departments (ED) and they may pose a diagnostic and management problems. It has been reported that more than twothirds of the patients with FB are men in their $3^{\text {rd }}$ and $4^{\text {th }}$ decades of life [1]. The age range of the patients with retained rectal FB is between $5-90$ years $[1,2]$.

In this study we describe the removal of a self-inserted armpit rollon deodorant bottle from the rectum of a 16 year-old boy. The topic is also discussed under the light of relevant literature.

\section{Case}

A 16-year-old boy was admitted to our ED after he had inserted an armpit deodorant bottle into his rectum 6 hours before presentation to the hospital. He complained slight abdominal an anal pain and denied any form of sexual abuse. An abdominal and pelvic X-ray revealed a bottle-shaped object with its roll-on tip looking upwards without any signs of free abdominal air (Figure 1). Abdominal examination was normal and digital rectal examination revealed a FB palpable $4 \mathrm{~cm}$ from the anus with diminished anal tonus. A trial for removal of FB in ED was unsuccessful and removal of the bottle under general anesthesia was planned. The patient was positioned lithotomy and abdominal compression from above together with digital rectal manipulation of the FB was performed (Figure 2). The FB was handled with a blunt Kocher clamp and extracted (Figure 3). The diameter of the bottle was $44 \mathrm{~mm}$. After removal of the FB endoscopic examination was performed in order to detect any mucosal lesions including tears or perforation and hopefully the mucosa was found to be intact. The patients was advised to consult a psychiatrist and discharged from the hospital on the first postoperative day.

\section{Discussion and Conclusion}

Described sporadically in published records, rectal FB insertion dates back to as early as the $16^{\text {th }}$ century when Haft and Benjamin reported a case with rectal FB [3]. In 1880, Poulet included several chapters on the topic in his book and in 1919 Smiley published a case with glass tumble inserted into the rectum $[4,5]$. Since then FB insertion into rectum is no longer considered an uncommon reason for emergency department admissions and its incidence is rising. In a recent report, of traumatic rectal injuries seen in ED, 19\% were found to be secondary to FB insertion [6].

Rectal insertion of FBs is commonly seen in males with an age range of 5-90 years [1,2]. Emphasizing the distinct male preponderance in these cases, in a recent systematic review, it was noted that ratio of men to women with rectal FB insertion was 37:1 [3]. There is a bimodal age distribution of these cases observed in twenties for anal erotism and in the sixties mainly for prostatic massage or for the purpose of fecal disimpaction [7].

It is crucial to establish the motivation for foreign object insertion for a successful patient management. The causes are namely sexual gratification commonly seen in the twenties, as a result of suicidal or nonsuicidal self injurious behaviour, psychosis with or without mood disturbance, as a consequence of depressive or factitious disorder, malingering for the sake of "secondary gain" and in patients with cognitive disorders [8-13]. Another categorization of rectal FB insertion includes sexual or nonsexual involuntarily inserted FBs. There are wide variety of materials for voluntarily rectal insertions for sexual purposes and include plastic or glass bottles, cucumbers, carrots, wooden or rubber objects etc. Patients with involuntarily inserted rectal FBs are usually seen as a result of rape or sexual assault [14]. Nonsexual FB insertions may be seen in patients with the behaviour of body packing or drug traffickers [1]. Children, elderly people or mentally ill persons are candidates for involuntary nonsexual FB insertion. Other causes of FB insertion include children who usually insert FBs for the sake of simple curiosity as a consequence of misguided attempts at contraception, abortion or self-treatment of anal or urinary symptoms [2,15-17]. Although the presented case denied the self-sexual arousal, we speculate that this is 


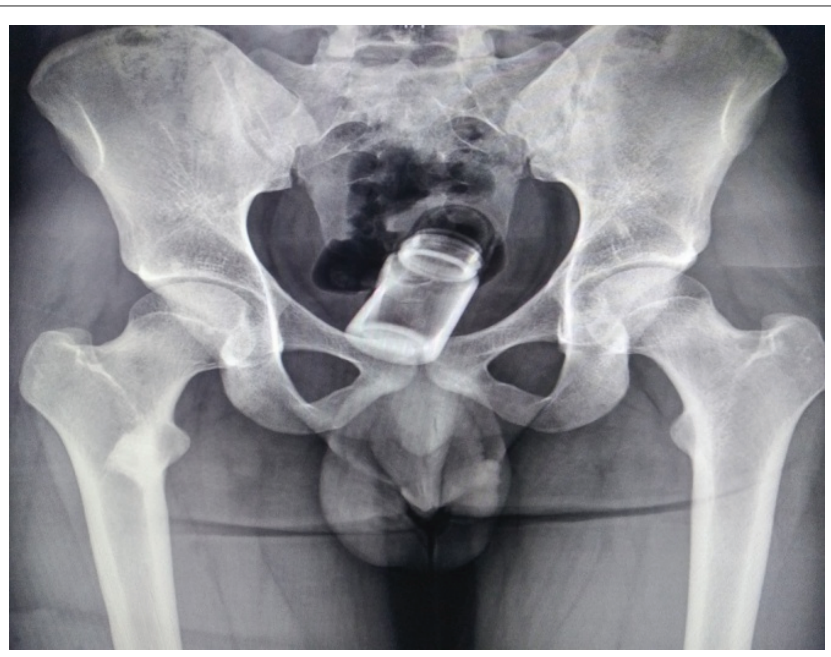

Figure 1: X-ray showing an armpit deodorant bottle with its roll-on tip looking upwards.

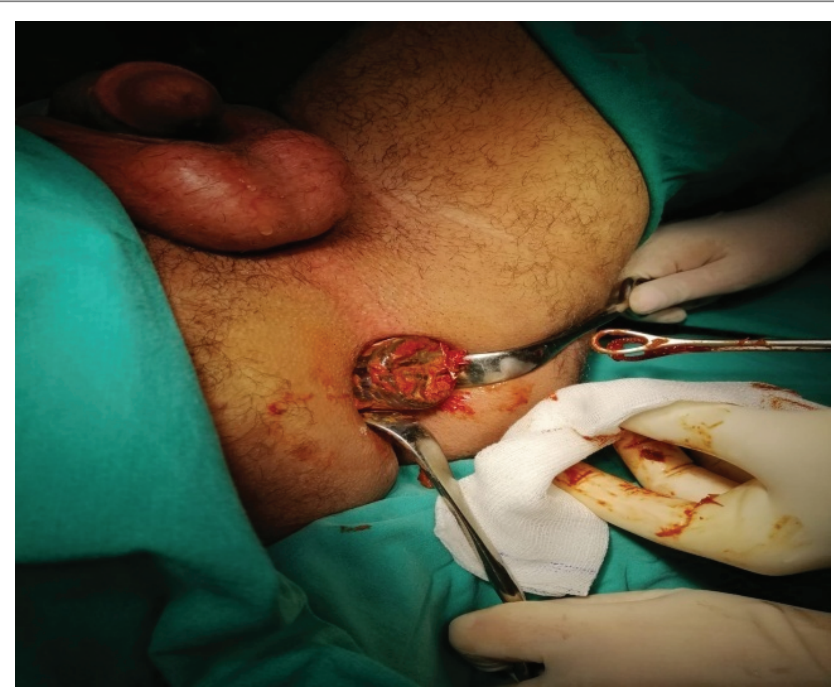

Figure 2: Operative view showing the patient positioned as lithotomy together with digital rectal manipulation of the FB. Note the foreign object is being pulled out.

the reason in our case because the anal tonus during rectal examination was found to be decreased and a psychiatric consultation was planned after discharge from the hospital.

These patients are often reluctant to disclose their situation and usually complain of anal or abdominal pain. Rectal bleeding may also be observed during assessment of the patients [18]. Anal pain was the presenting symptom in our case. Patients with rectal FB usually attempt to remove FBs by themselves and this may cause late hospital admissions. Rectal examination is essential in diagnosing these cases. But it should be performed after obtaining X-ray of the abdomen. A sharp unidentified foreign object like a broken beer bottle retained in rectum may cause harmful effect for attending surgeon during rectal examination if it is performed prior to X-ray. So it is highly recommended that X-ray should be obtained prior to digital rectal examination. During rectal examination careful attention should be

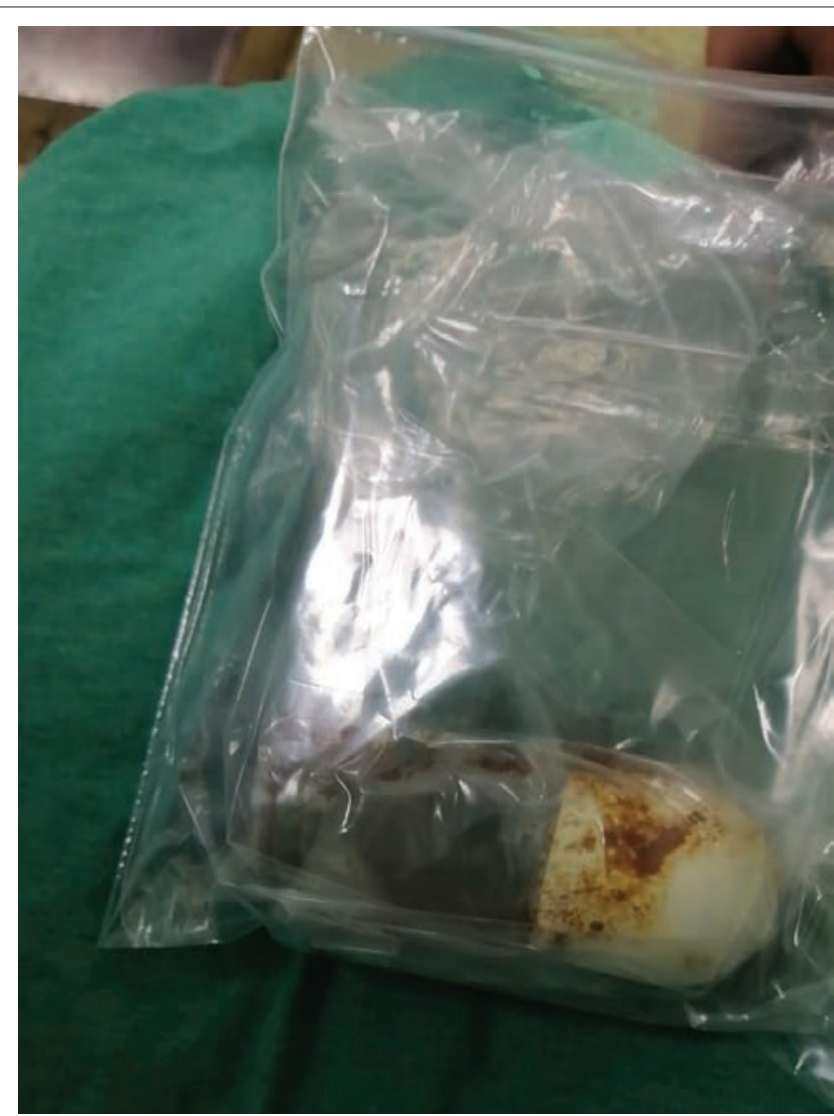

Figure 3: A roll-on armpit deodorant bottle after removal from the anus.

paid to the status of the sphincter especially in patients with repeated rectal FB insertions. Rectal tonus was found to be diminished in our case pointing a repeated stimulation. Although such an approach has been suggested, generally speaking, enemas or stimulant suppositories are not recommended which may cause extensive injury [1]. Although infrequently seen, there are serious complications related to rectal insertion of FBs. These are rectal mucosal tears, disruption of sphincteric complex, fecal incontinence, perforation or bleeding.

Although it is generally admitted that partial thickness rectal injuries do not require intervention, in a recent series comprising 33 cases with retained rectal foreign objects, due to the difficulty in excluding full thickness injuries, some surgeons treated the patients with partial thickness injuries operatively which was associated with significantly longer hospital length of stay and unless full thickness injury is conclusively identified, nonoperative management after a retained rectal foreign body was recommended [19]. If nonoperative management fails then comes the necessity of removing the foreign object from the rectum. There are numerous treatment choices in removal of foreign object from rectum. Transanal removal of FB is the most common procedure in the management of these patients [20]. This may be performed in ED as the patient is awake or as an outpatient basis with intravenous sedation and perianal nerve blocks. In children, general anesthesia is usually applied during removal of rectal FB. Lithotomy position is useful and digital rectal examination together with abdominal pressure from above is helpful in squeezing the FB distally. A grasping clamp like a Kocher clamp is useful in removing the FB as is the case in the presented study. Several other 
approaches have been reported as a choice of removal of rectal FB and these include a foley catheter technique, injection of air above the object, use of magnets, Sengstaken-Blakemore tube technique or a use of an obstetrical vacuum device [20-23].

Surgical intervention for removal of FB may be necessary if there is inability to remove the object, if there is perforation or peritonitis. The choices of surgical treatment include laparotomy and squeezing the FB distally, colotomy with removal of FB and primary closure, if there is excessive peritoneal contamination due to perforation proximal diversion may be performed. Laparoscopic assisted transanal removal may also be another choice of surgical intervention. In this method the FB is pushed from above to assist removal transanally [24].

Following successful removal it is vital to perform endoscopic examination to evaluate the mucosa for local damage, active bleeding, ischemia, perforation or detecting an additional retained FB. Endoscopy may provide an opportunity to avoid unnecessary abdominal exploration.

In conclusion, rectal FBs may present a difficult diagnostic and management dilemmas due to delayed presentation, wide variety of retained FBs and wide spectrum of the injuries they may produce. It is likely that the incidence of this clinical entity will rise and an increasing trend will be encountered in most hospitals in future. Therefore frontliners of health providers dealing with such kinds of patients should be well informed about this and a prompt pediatric surgical consultation is recommended and the patient should be treated accordingly.

\section{References}

1. Goldberg JE, Steele SR (2010) Rectal Foreign Bodies. Surg Clin N Am 90: 173-184.

2. Hamid R, Bhat N, Wani SA, Baba A (2014) Unusual rectal foreign body in a child. J Pediatr Surg Case Rep 2: 391-393.

3. Kurer MA, Davey C, Khan S, Chintapatla S (2010) Colorectal foreign bodies: a systematic review. Colorectal Dis 12: 851-861.

4. Poulet A (1880) A Treatise on foreign bodies in surgical practice 1880. William Wood, New York.

5. Smiley O (1919) A glass tumbler in the rectum. JAMA 72: 1285.

6. Yacobi Y, Tsivian A, Sidi AA (2007) Emergent and surgical interventions for injuries associated with eroticism: a review. J Trauma 62: 1522-1530.

7. Akhtar MA, Arora PK (2009) Case of Unusual Foreign Body in the Rectum. Saudi J Gastroenterol 15: 131-132.

8. Melamed Y, Dalyahu Y, Vaiman R, Bzura G, Bleich A (2007) Foreign objects in the vagina of a mentally ill woman: case series. Gen Hosp Psychiatry 29: 270-272.

9. Waraich NG, Hudson JS, Iftikhar SY (2007) Vibrator-induced fatal rectal perforation. N Z Med J 120: U2685.
10. Bloch Y, Lauder A, Ratzoni G (2005) How many pins? A case report of a girl who swallowed more than 50 straight pins in a suicide attempt. Int J Adolesc Med Health 17: 295-297.

11. Nielsen SU, Rasmussen M, Hoegberg LC (2010) Ingestion of six cylindrical and four button batteries. Clin Toxicol 48: 469-470.

12. Khan SA, Davey CA, Khan SA, Trigwell PJ, Chintapatla S (2008) Munchausen's syndrome presenting as rectal foreign body insertion: a case report. Cases J 1: 243.

13. Rada RT, James W (1982) Urethral insertion of foreign bodies. A report of contagious self-mutilation in a maximum-security hospital. Arch Gen Psychiatry 39: 423-429.

14. Coşkun A, Erkan N, Yakan S, Yıldırım M, Cengiz F (2013) Management of rectal foreign bodies. World J Emerg Surg 8: 11.

15. Mukerji G, Rao AR, Hussein A, Motiwala H (2004) Self-introduction of foreign body into urinary bladder. J Endourol 18: 123-125.

16. Kenney RD (1988) Adolescent males who insert genitourinary foreign bodies: is psychiatric referral required? Urology 32: 127129.

17. Sharma UK, Rauniyar D, Shah WF (2006) Intravesical foreign body: case report. Kathmandu Univ Med J (KUMJ) 4: 342-344.

18. Polsdorfer JR, Gale T (2011) Foreign objects. Gale Encyclopedia of Children's Health 2006.

19. Schellenberg M, Brown CVR, Trust MD, Sharpe JP, Musonza T, et al. (2020) Rectal Injury after Foreign Body Insertion: Secondary Analysis From the AAST Contemporary Management of Rectal Injuries Study Group. J Surg Res 247: 541-546.

20. Lake JP, Essani R, Petrone P, Kaiser AM, Asensio J, et al. (2004) Management of retained colorectal foreign bodies: predictors of operative intervention. Dis Colon Rectum 47: 1694-1698.

21. Rodríguez-Hermosa JI, Codina-Cazador A, Ruiz B, Sirvent JM, Roig J, et al. (2007) Management of foreign bodies in the rectum. Colorectal Dis 9: 543-548.

22. Feigelson S, Maun D, Silverberg D, Menes T (2007) Removal of a large spherical foreign object from the rectum using an obstetric vacuum device: a case report. Am Surg 73: 304-306.

23. Ruiz del Castillo J, Sellés Dechent $R$, Millán Scheiding $M$, Zumárraga Navas P, Asencio Arana F (2001) Colorectal trauma caused by foreign bodies introduced during sexual activity: diagnosis and management. Rev Esp Enferm Dig 93: 631-634.

24. Rispoli G, Esposito C, Monachese TD, Armellino M (2000) Removal of a foreign body from the distal colon using a combined laparoscopic and endoanal approach: report of a case. Dis Colon Rectum 43: 1632-1634. 